\title{
An Empirical Study on Influencing Factors of Knowledge Sharing in Virtual Learning Community
}

\author{
Bo Shen ${ }^{*}$
}

School of Information Technology, Jiangxi University of Finance and Economics, Nanchang, 330032, P.R. China

\begin{abstract}
Increasing organizations and educational institutions have implemented virtual learning communities to encourage knowledge sharing. Virtual Learning Community was able to serve the learning goals of community members by relying on the knowledge sharing. In this paper, some individual factors and environmental factors were used to study the knowledge sharing among community members. In virtual learning community, the sense of community and trust are important indicators for the development of community, and the members of mature community tend to have strong a sense of community and trust. Ten hypothesizes and the way of questionnaire survey were presented to explore the impact of social interaction, perceptual learning, trust, a sense of community and self-efficacy for knowledge sharing among members in community. The empirical results show that social interaction behavior between members has a significant role in promoting trust and a sense of belonging, and trust, a sense of community and a sense of self-efficacy among members has a significant effect to the knowledge sharing in virtual learning community, while a sense of self-efficacy among members in the virtual learning community is largely affected by the learning community perception.
\end{abstract}

Keywords: Empirical study, knowledge sharing, virtual learning community.

\section{INTRODUCTION}

The rapid development of network information technology has increased the number and complexity of knowledge, prompting the prosperity and development of virtual communities. Due to the height of the virtual community openness and freedom, it has become a spiritual paradise of netizens to express ideas and share personal knowledge, and thus the formation of a mutual exchange and caring personal relationships. At present, virtual learning community which the basic purpose is learning and education has open up an unprecedented free and interactive virtual learning environment for people. In recent years, virtual learning community has been a great development, domestic and international research on virtual learning community is also very rich, and combining with knowledge management is a hot topic of research in recent years. In virtual learning communities, knowledge-sharing activities among community members is an important content, it is an important indicator of the degree of community's development. However, in today's virtual learning environment, the atmosphere of knowledge sharing among community members is not optimistic, the degree of interaction among members is not high, which seriously affected the member's learning efficiency. To solve these problems faced in virtual learning communities, improving knowledge sharing ability among members, we need to study the influencing factors of knowledge sharing in virtual learning community. In this paper, the impact factors were used to study the knowledge sharing among community members.
In recent years, the academic study on virtual learning community for knowledge sharing has made some achievements, but conditions and methods of knowledge sharing in virtual learning community have not systematically studied, and in the process of research lack of attention to people. In the paper, the research focused on the affecting factors of sharing knowledge in virtual learning communities and this particular platform, combined with psychological and behavioral characteristics of people, the paper proposed a knowledge sharing model proposed, making knowledge sharing from a personal level spread to organizational level, and ultimately promote the exchange and sharing of virtual learning community among learners and communities of knowledge and innovation, also provide theoretical guidance significance to build the knowledge sharing of virtual learning communities.

\section{THEORY REVIEW AND RESEARCH MODEL}

\subsection{Virtual Learning Community}

The concept of virtual learning community is derived from the virtual community, it is a unique practice community focus on learning. Rheingold described virtual community as social groups based on personal emotional communication and relationships networks [1]. Currently, the virtual community has been very popular, and its application has been extended to many areas, including social, educational and entertainment fields. One of the goals of virtual learning community is to encourage knowledge sharing, so the valuable knowledge in networks can be effectively developed. From the perspective of computer information systems, Blanchar and Cook defined virtual learning community as a group composed by students, teachers, instructors and teach- 
Fig. (1). Theoretical model.

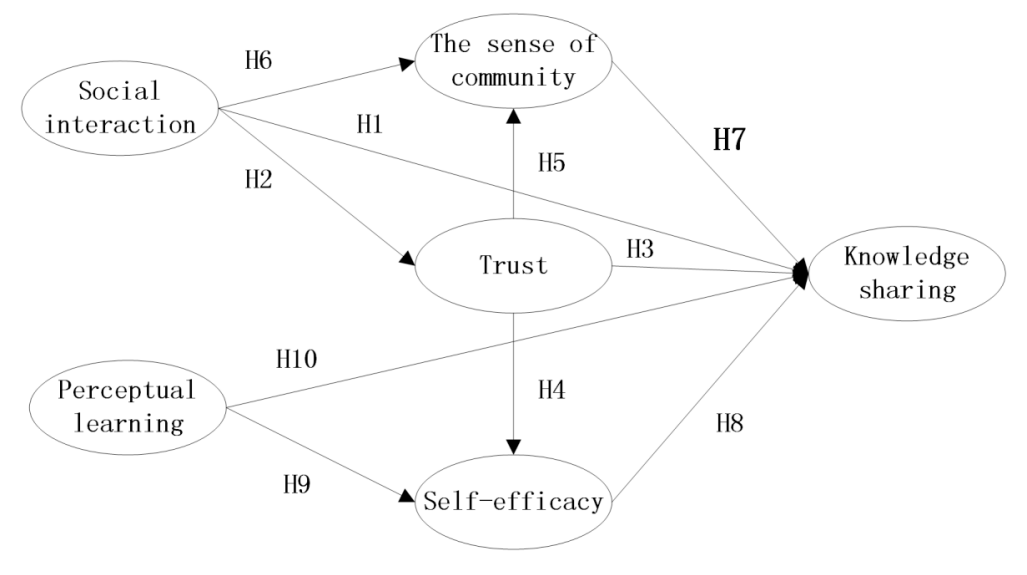

ing assistants, members of the group use computer information technology to interact with each other [2]. Learners and facilitators communicate and learning through community exchange platform or network communication tools (such as QQ, blog, microblogging, post bar, forums, etc.), sharing knowledge and experience to achieve the purpose of teaching and learning. From the current point of view, the virtual learning community has no uniform definition, generally refers to the application of the virtual community in the field of education, which belongs to a learning community. Based on the understanding of people on the Internet "informal" learning and interaction education mode virtual learning community are generated, it is a kind of transcend time and space constraints and lifelong learning for the purpose of the education mode, but also achieve a favorable platform for tacit knowledge transfer and sharing in the virtual community, it creates a good condition for the members of the learning and communication. Gan believes that virtual learning community's learning purpose is stronger than virtual community's, it is a combination of online learning and virtual community, the place of some people who have a common language and value tendency communicate with each other in the virtual space based on specific teaching strategies [3].

\subsection{Construction of Theoretical Model}

Combined with previous studies on knowledge sharing factors, some individual factors and environmental factors were used to study the knowledge sharing among community members. From Wang Lei and others' knowledge sharing factors analysis on the virtual learning community shows that maturity, trust between members and the community's internal motivation of members is the direct factors influencing the students' knowledge sharing [4]. In the virtual learning community development stage, the sense of community and trust are important indicators in the process of development, and the members of mature community tend to have strong a sense of community and trust, of which the sense of community is the key environmental factor to stimulate knowledge sharing and learning, the sense of community and trust are the indispensable factors to maintain the continuous development and prosperity of the virtual learning community. According to the social cognitive theory and social motivation, empirical research results show that as the individual internal motivation factors of self-efficacy which is the individual internal motivation factors and performance target has close direct contact $[5,6]$. In the virtual learning community, the social interaction of members is an important premise, but learning is an important objective of construction of virtual learning community, this paper used the virtual environment for learning the perception of members as the evaluation indicator of learning, namely perceived dimensions of learning, it is an indicator of individual factors and environmental factors.

In summary, this paper carries on dimensions of knowledge sharing influence between members of the factor analysis from the individual factors and environmental factors in the social interaction, perceptual learning, trust, a sense of community, a sense of self-efficacy, namely social interaction and perceptual learning as the antecedent variables, sense of community, trust and self-efficacy as intermediary variables, knowledge sharing as the outcome variable and constructs a theoretical model of this paper in Fig. (1).

\subsection{Hypothesizes}

\subsubsection{Social Interaction}

In virtual learning community for the purpose of learning, with a purpose of communication between members and the theme, they through a variety of methods in community platform to share information and knowledge, maintain a long-term interaction with other members. In a closely relationship between the members of virtual learning community, the interaction between members is the main way to obtain knowledge of community members, this process also contributed to speed the flow of knowledge in virtual learning communities. From the frequency of interaction and relationships between members, the members often participate in interactive tend to guide the interaction in the learning process, and are willing to share their knowledge. Therefore, the depth of interaction between members also affects the depth of knowledge sharing.

Quigley and other scholars believe that knowledge sharing activities in organization possible occur only under good interpersonal relations, communication and interaction between members of the organization can promote them to share knowledge, and interactive communication skills of members should be deemed one of the core abilities to promote knowledge sharing [7]. Interaction is the premise of the knowledge sharing of virtual learning community, no inter- 
action among members of the community would have no knowledge sharing. The development of frequent interaction between members can strengthen the close relationship of them, reduce the cognitive uncertainty, and encourage them to share community knowledge and personal point of view. From Duncan and Moriarty's point of view, the members of the knowledge sharing is the product of the interaction and relationship [8].

Hypothesize 1 (H1): The social interaction of members have positive effect on knowledge sharing in virtual learning community.

\subsubsection{Trust}

Because of the virtual nature of virtual learning community, there is the problem of trust in the community interactive space. Trust is the link to maintain relationships with other members of the virtual learning community, but also made important condition for success. In the virtual space, because it is easy to generate distrust between spatial and temporal separation, interpersonal communication and knowledge sharing among community members will have some negative impact. Most members of virtual learning communities have the same preferences for certain themes or consistent interest, they often share ideas and experiences, interactive very frequently, so it will have a higher sense of trust between each other [9].

Davenport pointed out that trust is essential for knowledge sharing, if any behavioral lack of trust between people, organizations have little chance of success [10]. Mutual trust is the soul of knowledge transaction [11]. Xu Mengxiang have studied knowledge sharing in virtual learning community based on social cognitive theory, found that type identity trust plays a key role in knowledge sharing [12]. In the virtual learning community members put a lot of trust in each other's' feelings, and they care about the interests of members and believe that the true value of this feeling lies, but they also think that the existence of such feelings are mutual. Therefore, based on this recognition among members of the trust also showed interaction of affection between members. Abrams and others defined interpersonal trust as ability and kindness, this thought and based on the identity of the trust is the same, personal ability and kindness can effectively promote the creation of knowledge in social network and share [13].

In virtual learning communities, trust is an important environmental features. In social cognitive theory, the trust can be seen as an environmental factor, and knowledge sharing self-efficacy is an individual factor, according to this theory, environmental factors will affect individual factors [12]. An empirical research, there are many scholars have studied the relationship between trust and self-efficacy. Cheung and Chan using social cognitive theory and other theories in charitable contributions examined some related factors in social cognitive, the results show that trust in self-efficacy has a very significant impact on the relationship, which can evoke trust contributions cognitive self-efficacy [14]. Pavlou and Fygenson extended the theory of planned behavior to explain the process of electronic commerce to be accepted by people, they think that trust is a prerequisite for-perceived behavioral control, this kind of behavior control consist of two important factors: self-efficacy and control, and in the results only prove trust to the effect of control force [15].

In the virtual learning community, the trust relationship between members is an important factor in maintaining community operating. Trust between members is meant to members will provide valuable information and participate in community interaction, when a member trusted by the community, he will be more willing to participate in community activities, and strengthen the relationship with other members, individuals in the community's influence also changed, the number of times to participate in the activities of more frequent [16]. Hu Fan Gang's empirical studies have shown that the interaction between learners can strengthen the relationship between members and feelings of the community in the virtual community education, and also to promote a sense of community continues to strengthen [17]. In the research on the sense of community studied by Blanchard and Markus, they believed that a sense of trust among members can eliminate uncertainties among the community, then community members will generate emotional dependency, the study results clearly indicate that the trust between members can have an important impact on the sense of community [18]. In this study, a sense of trust and a sense of community among the members plays an important role in the development of community, a sense of trust among members can deepen the relationship between members, influence the behavior of members to participate in community activities, also contributed members of the community to deepen the emotional dependency, members with a strong sense of community usually move active in the community, both of which are to some extent influenced the development of the community.

In summary, put forward the following hypothesizes:

Hypothesize 2 (H2): Social interaction between members has a positive influence on trust relationship

Hypothesize 3 (H3): Trust between members has a positive influence on knowledge sharing.

Hypothesize 4 (H4): Trust between members has a positive influence on self-efficacy of knowledge sharing.

Hypothesize 5 (H5): TRUST between members has a positive effect on the sense of community.

\subsubsection{Sense of Community}

In the process of the formation and development of virtual learning community, a sense of community is link to connecting community members and to maintaining close ties between the members. Foreign scholars Jennifer E. Cross defined a sense of community as people's emotional ties to residence, including the emotional attachment and intimacy [19]. In virtual learning communities, community members need a sense of community to this psychology is same. In virtual learning community, a sense of community means that community members are willing to participate in community activities and become a member of the community, which is based on personal emotional psychological tendencies, including the emotional dependence of community identity and self-identity [20]. 
Interaction of members is not only a core element of the formation of community, but also an important condition to promote a sense of community, without interactions there will no emotional communication among members, it is difficult to form a strong sense of community.

For the purpose of virtual learning community is learning, it is a virtual community to provide an informationsharing, communication and help for community members, in other words, the existence of the virtual learning community is to solve practical problems in the process of learning and put it together, in fact, it is can promote learning and knowledge sharing among members. Virtual learning community members not only provide knowledge to others and to solve the problems of others, but also to obtain the information they need, maintain a virtual learning community members and attract potential members to join the community by constantly enrich useful knowledge, encourage members knowledge contribution. Chai and Kim found that a strong sense of community will stimulate members to participate in knowledge sharing [21]. When community members discovered that he belongs to a particular community, they put themselves or other members of the community as a collective, and will take the time and effort to do something good for the community. Belonging to the community will train members of the community's identity, so that they are willing to share knowledge with other members of community [22]. Wasko and Faraj found that people with a strong sense of belonging in social networks are more likely to share their knowledge with other members, because they think it is they are doing the right thing [23]. This paper argues that long-term continuous interaction of community members usually have a strong sense of community, this sense of community can also stimulate them to share knowledge with other members.

Hypothesize 6 (H6): Social interaction has a positive influence on the sense of community of members.

Hypothesize 7 (H7): A sense of community in virtual learning community members have positive influence on knowledge behavior between members.

\subsubsection{Self-Efficacy}

Self-efficacy is an important content of social cognitive theory, it refers to the individual at the completion of a task, to evaluate whether he has ability to accomplish a specific goal and has a belief to complete the goal [24]. Domestic and foreign scholars generally believe that a sense of selfefficacy Bandura proposed is an individual's potential perception, namely the ability to self-assess when they encounter problems, and then make the appropriate behavior according to their own judgment, reflect a degree of selfconfidence.

In the virtual learning community, self-efficacy is the psychological manifestation of members to participate in community activity. Members participate in the activities of community will have to deal with the problem for the ability of self-assessment, this process can produce the corresponding drive and guide the individual behavior, this behavior is brought by the self-efficacy, namely self-efficacy can affect perception behavior of members. In the process of members to participate in the community of knowledge sharing, if members considered that they have strong ability of knowledge sharing, they will play this ability in the subconscious, also have confidence in the knowledge sharing, and each individual in the community of the strength of self-efficacy is different [25].

In this study, a sense of self-efficacy of member knowledge sharing is a faith and a reflection that have the ability to provide valuable knowledge. There are many scholars study shows that individuals have the expertise and ability are more likely to provide a high level of knowledge useful in the virtual community, in the process of sharing useful knowledge to the community, members can be more confident to do more matter [25]. This strengthened the perception of self-efficacy will encourage members to share their knowledge to other members [26]. Therefore, this study presents the following Hypothesize:

Hypothesize 8 (H8): Virtual learning community members' knowledge sharing self-efficacy positive affects knowledge sharing behavior of its members.

\subsubsection{Perceptual Learning}

In this paper, perceptual learning is defined as a person to learn the set of beliefs and emotions, is a kind of retrospective evaluation of learning experience [27]. This definition comes from two sources: the cognitive and social-emotional [28]. Cognitive sources reflect new knowledge gained will have a new understanding and some other cognitive processes, social-emotional origin reflects the experience and emotions, including the interaction of factors, or an innovative study of the current state inspiration. In previous research, there are many signs that the "learning" (measured by performance indicators) and "perceptual learning" (measured by presenting sensory and perception) is not the same meaning, they are independent and not related. Rovai and Barnum think that using performance indicators to measure the standard of learning is not the best, they proposed to use "perceptual learning" instead of performance indicator targets [29]. Jiang and Ting through research found that "perceptual learning" targets and performance indicators to measure the learning is not relevant [30]. According to the above analysis, in this study, using the "perceptual learning" to measure the learning in virtual learning community.

In virtual learning community for the purpose learning, Community environment, community members' support for learning has important influence on members of the perceptual learning. Wang believes a good support learning communities should be a learning atmosphere that encourages the exchange of knowledge among members, the members of this atmosphere to strengthen the perception of learning in a virtual environment, and trigger their intrinsic motivation for knowledge exchange [31]. More specifically, when learners in virtual learning communities perceive that they are positive learners, their power will be higher, they also try to analyze, comment and manage some of the information, and they are transformed into valuable knowledge [32]. Later scholars Mancuso-Murphy [33], Vaughan [34], Elvers [35], also agreed that a more dynamic individual learning in a virtual learning environment can exhibit autonomous, selfdiscipline, self-directed and more confident to take learning responsibility, which is a sense of self-efficacy enhancing performance. 
Self-efficacy is the reflection of individual an intrinsic motivation based on their ability and confidence, and through the emotion priming self-efficacy is an important source of its formation. Perception of learning to promote learners become more active, they has a greater expectation on learning, in virtual learning community given priority to with communication and interaction, Perceptual learning more deeply the learners were more willing to participate in community discussion, to express their views, Knowledge of communication with other members until you reach the consensus of opinion, this kind of behavior as well as to promote the spread of knowledge within the scope of the field. Based on the above analysis, we put forward the following hypothesizes:

Hypothesize 9 (H9): members of the virtual learning community for learning perceived positive impact on members of knowledge sharing self-efficacy.

Hypothesize 10 (H10): Virtual Learning Community members perceived positive impact on learning knowledge sharing among community members.

\section{RESEARCH METHODS}

This research mainly adopts questionnaire investigation to collect data, the survey began in November 1, 2013, ended in December 31, 2013. There are 300 questionnaires, 250 were recovered, the recovery rate is $83.33 \%$. The investigation object is being used or participated in the virtual learning community, most of them are students, fill in the form of questionnaire is Internet links page to fill in, each project is set to mandatory, by determining the collected data of 250 are valid data. Distribution of the sample data is mainly based on the individual level of each member are described, including gender, age, education, frequency of use to access the community and the time. In the questionnaire design process, the antecedent variables of social interaction and perceptual learning respectively reference to Rourke and Anderson, Swan [36, 37] scale, consistency coefficient of each dimension is greater than 0.80 , the intermediary vari-
Table 1. Cronbach $\alpha$ of each variable.

\begin{tabular}{|c|c|}
\hline Latent Variables & Cronbach $\boldsymbol{\alpha}$ \\
\hline \hline Social interaction & 0.840 \\
\hline Perceptual learning & 0.905 \\
\hline Members' a sense of community & 0.932 \\
\hline Community Trust & 0.890 \\
\hline Self-efficacy & 0.910 \\
\hline Knowledge Sharing & 0.899 \\
\hline
\end{tabular}

ables include three members a sense of community, community trust, self-efficacy. A sense of community continues to use the Koh and Kim [38] scale, scale consistency coefficient greater than 0.85 . Community trust scale is used and followed Hsu Ju scales [39], the consistency coefficient scale greater than 0.87 . Self-efficacy is followed Kankanhalli and Tan used the Scale [40], the reliability coefficient was 0.93 . Knowledge sharing as a result of the variables in this paper, the variable reference $\mathrm{Hu}$ and Ju to measure knowledge sharing behavior scales [39].

\section{DATA ANALYSIS}

\subsection{Validity Analysis}

The use of SPSS 19.0 for each variable validity analysis, from the measurement results, the overall consistency coefficient (Cronbach $\alpha$ ) values for all measured variables are greater than 0.8 , can be seen between the measurement scale has high internal variables consistency, the reliability of the test results the standard requirements. Wherein the overall $\alpha$ values as shown in Table $\mathbf{1}$ for each variable.

\subsection{Model Test}

In this paper, AMOS 17.0 software and ML maximum likelihood estimate of the model parameters. According to

Table 2. Model parameter estimation results.

\begin{tabular}{|c|c|c|c|}
\hline Model Test & Hypothesis Path & Standardized Regression Coefficients & Index Evaluation \\
\hline $\mathrm{H} 1$ & Social Interaction $\rightarrow$ Knowledge Sharing & 0.125 & Accept H1 \\
\hline $\mathrm{H} 2$ & Social Interaction $\rightarrow$ Trust & $0.427 * * *$ & Accept H2 \\
\hline H3 & Trust $\rightarrow$ knowledge sharing & $0.350 * * *$ & Accept H3 \\
\hline H4 & Trust $\rightarrow$ Self-efficacy & $0.405 * * *$ & Accept H4 \\
\hline H5 & trust $\rightarrow$ Sense of community & $0.491 * * *$ & Accept H5 \\
\hline H6 & Social Interaction $\rightarrow$ Sense of community & $0.396 * * *$ & Accept H6 \\
\hline H7 & Sense of community $\rightarrow$ knowledge sharing & $0.439 * * *$ & Accept H7 \\
\hline H8 & Self-efficacy $\rightarrow$ knowledge sharing & $0.439 * * *$ & Accept H8 \\
\hline H9 & Perceptual learning $\rightarrow$ Self-efficacy & $0.443 * * *$ & Accept H9 \\
\hline $\mathrm{H} 10$ & Perceptual learning $\rightarrow$ knowledge sharing & 0.145 & Accept $\mathrm{H} 10$ \\
\hline
\end{tabular}

$(* * * \mathrm{P}<0.001)$ 
the basic principle of structural equation model fitting, the comprehensive evaluation model fitting effect, validate the model assumptions path as shown in Table $\mathbf{2}$.

In the model fitting effect index, index of inspection is the main test, the fitting effect of absolute relative fitting effect test and alternative index test. In the absolute fit index, the requirements of fit index GFI and adjust the fit index of AGFI value is greater than 0.9, the relative fit index NFI and a proxy for the CFI value should be greater than 0.9 , the root mean square error of myopia RMSEA value must be less than 0.1 , value less than 0.08 indicates that the model fitting effect is good. As shown in Table 2, the value is 2.124, which is less than 3; the value is GFI, NFI and AGFI are $0.865,0.885$ and 0.859 , respectively, were less than 0.9 , but higher than the lower limit of the minimum 0.85; IFI = 0.935 , CFI $=0.931$, were greater than 0.9; RMSEA value is 0.067 , less than 0.08 . It can be seen, the effect of the model fit well can be accepted. As can be seen from Table 2, it is assumed in the present study $\mathrm{H} 1$ and $\mathrm{H} 10$ model has not been verified, other hypothesizes have been verified.

\section{CONCLUSION}

This study explores the 10 hypothesizes proposed by empirical research methods, including eight hypothesizes has been verified, there are two hypothesizes have not been verified. In the hypothetical model of this paper, mediating variables trust, a sense of community and self-efficacy have a significant role in promoting knowledge sharing in virtual learning community, trust between members of mediating variables also through an intermediary role between the pair virtual learning community knowledge Sharing play influence, antecedents of social interactions between a sense of community of members and trust has a significant role in promoting, but in a virtual learning community, a sense of self-efficacy among community members are largely perceived by members of the learning impact.

In virtual learning community, social interaction is an essential element of learning in virtual learning community, learning occurs in members of the community to participate in interactive situations in. Interaction between members is a key factor in the formation of a virtual learning community, while social interaction is affected community members culture, a sense of community members to form an important prerequisite. Perceptual learning is a person to learn the set of beliefs and emotions, it is the feeling of the members perceive virtual environment in learning support. A good support learning in virtual community should be a learning atmosphere that encourages the exchange of knowledge among members, this atmosphere to strengthen the perception of learning in a virtual environment, and trigger their intrinsic motivation for knowledge exchange.

In virtual learning community, a stronger sense of trust relationships between members, the more opportunities are shared between members, people are more willing to participate in knowledge-sharing community activities, also can improve the ability of knowledge acquisition and absorption of members, and reduce sharing costs. For every member of the community, they participate in community activities, it is very important to integrate with the community, to get a sense of community. A sense of community reflects continued recognition and emotional dependence. Community members with a strong sense of community are more willing to comply and maintain order in the community, through their actions are more willing to participate in community knowledge-sharing. Self-efficacy is an important concept derived from social cognitive theory, it can be said that the individual at the time of the completion of a task to complete the objectives required for a conviction ability.

In this study, self-efficacy is defined as a faith to provide valuable knowledge to other members. In virtual learning community, members continue to participate in the community by addressing issues of discussion and to share and express their views, which also makes the members have a major impact on the community, becomes the central figure in the community from a peripheral participant in this process, members will be able to facilitate knowledge sharing in the development of partnerships and trusts. These positive relationships for knowledge sharing in virtual learning communities is very important.

\section{CONFLICT OF INTEREST}

The author confirms that this article content has no conflict of interest.

\section{ACKNOWLEDGEMENTS}

Declared none.

\section{REFERENCES}

[1] H. Rheingold, The Virtual Community: Homesteading on the Electronic Frontier, Addison Wesley Publishing Company, 1993, pp. 28-52.

[2] A.L. Blanchard, and J.R. Cook, "Virtual learning communities centered within a discipline: Future directions", New Directions for Teaching and Learning, vol. 132, pp. 85-97, 2012.

[3] Y. Gan, and W. Wang, "Analysis and study on the multiple implications of virtual learning community", Modern Distance Education Research, vol. 5, pp. 10-15, 2005.

[4] L. Wei, and Z. Li, "Analysis of factors affecting students' knowledge sharing in virtual learning community", China Educational Technique \& Equipment, vol.18, pp. 26-28, 2011.

[5] Q. Qiu, C. Zhang, and Y. Wei, "Summary of researches on knowledge sharing in foreign countries", Information Studies: Theory \& Application, vol. 33, pp. 120-124, 2010.

[6] Y. Lan, and X. Feng, "Social network analysis on interactive structure in virtual learning communities", Neijin Science \& Technology, vol. 12, pp. 129-130, 2007.

[7] N.R. Quigley, P.E. Tesluk, E.A. Locke, and K.M Bartol, "A multilevel investigation of the motivational mechanisms underlying knowledge sharing and performance", Organization Science, vol. 18, pp. 71-88, 2007

[8] T. Duncan, and S.E. Moriarty, "A communication-based marketing model for managing relationships", Journal of Marketing, vol. 62, pp. 1-13, 1998.

[9] A. Armstrong, and J. Hagel, "The real value of online communities", Knowledge and Communities, pp.85-95, 2000.

[10] S. Davenport, J. Davies, and C. Grimes "Collaborative research programmers: building trust from difference", Technovation, vol. 19, pp. 31-40, 1998.

[11] T. H. Davenport, and L. Prusak, "Working knowledge: Managing What Your Organization Knows", Harvard Business School Press, Boston, MA, 1998.

[12] H. Meng-Hsiang, "Knowledge sharing behavior in virtual communities: The relationship between trust, self-efficacy, and outcome expectations", International Journal of Human-Computer Studies, vol. 65 , pp. 153-169, 2007. 
[13] L.C. Abrams, R. Cross, E. Lesser, and D.Z. Levin, "Nurturing interpersonal trust in knowledge-sharing networks", The Academy of Management Executive, vol. 17, pp. 64-77, 2003.

[14] C.K. Cheung, and C.M. Chan, "Social-cognitive factors of donating money to charity, with special attention to an international relief organization", Evaluation and Program Planning, vol. 23, pp. 241253, 2000.

[15] P.A. Pavlou, and M. Fygenson, "Understanding and predicting electronic commerce adoption: an extension of the theory of planned behavior”, MIS Quarterly, vol. 30, pp. 115-143. 2006.

[16] L. Zhao, Y. Lu, and Z. Den, "A study on sense of virtual community based on social capital theory", Chinese Journal of Management, vol. 6, pp. 1169-1175, 2009.

[17] F. Hu, and G. Li, "Empirical analysis on forming factors of sense of belonging in educational virtual communities", China Educational Technology, vol. 1, pp. 51-56, 2011.

[18] A.L. Blanchard, and M.L. Markus, "The experienced sense of a virtual community: Characteristics and processes", ACM SIGMIS Database, vol. 35, pp. 64-79, 2004.

[19] J.E. Cross, "Conceptualizing Community Attachment", Paper Presented at Rural Sociological Society Annual Meeting, Montreal, 2003.

[20] H. Liu, "Research on Sense of Belonging in Virtual Learning Community", M.S. thesis, Xi'an: Shaanxi Normal University, ON, China, 2009.

[21] S. Chai, and M. Kim, "A socio-technical approach to knowledge contribution behavior: An empirical investigation of social networking sites users", International Journal of Information Management, vol. 32, pp. 118-126, 2012.

[22] C.M. Chiu, M.H. Hsu, and E.T.G. Wang, "Understanding knowledge sharing in virtual communities: An integration of social capital and social cognitive theories", Decision Support Systems, vol. 42, pp. 1872-1888, 2006.

[23] M.M. L Wasko, and S. Faraj, "Why should I share? Examining social capital and knowledge contribution in electronic networks of practice", MIS Quarterly, vol. 29, pp. 35-57, 2005.

[24] A. Bandura, "Self-efficacy: toward a unifying theory of behavioral change", Psychological Review, vol. 84, pp. 191-215, 1977.

[25] D. Constant, S. Kiesler, and L. Sproull, "What's mine is ours, or is it? A study of attitudes about information sharing", Information Systems Research, vol. 5, pp. 400-421, 1994.

[26] G.W. Bock, and Y.G. Kim, "Breaking the myths of rewards: An exploratory study of attitudes about knowledge sharing", Information Resources Management Journal, vol. 15, pp. 14-21, 2002.
[27] A. Caspi, and I. Blau, "Social presence in online discussion groups: Testing three conceptions and their relations to perceived learning", Social Psychology of Education, vol. 11, pp. 323-346, 2008

[28] D.K. LaPointe, and C.N. Gunawardena, "Developing, testing and refining of a model to understand the relationship between peer interaction and learning outcomes in computer-mediated conferencing”, Distance Education, vol. 25, pp. 83-106, 2004.

[29] A.P. Rovai, and K.T. Barnum, "On-line course effectiveness: An analysis of student interactions and perceptions of learning", Journal of Distance Education, vol. 18, pp.57-73, 2003.

[30] M. Jiang, and E. Ting, "A study of factors influencing students' perceived learning in a web-based course environment", International Journal of Educational Telecommunications, vol. 6, pp. 317 338, 2000.

[31] Y.S. Wang, "Assessment of learner satisfaction with asynchronous electronic learning systems", Information \& Management, vol. 41, pp. 75-86, 2003.

[32] R. Lundin, "Being unreal: epistemology, ontology, and phenomenology in a virtual educational world", American Journal of Distance Education, vol. 12, pp. 53-65, 1998 .

[33] J. Mancuso-Murphy, "Distance education in nursing: an integrated review of online nursing students' experiences with technologydelivered instruction", The Journal of Nursing Education, vol. 46, pp. 252-260, 2007.

[34] N. Vaughan, "Perspectives on blended learning in higher education", International Journal on E-learning, vol. 6, pp. 81-94, 2007

[35] G.C. Elvers, D.J. Polzella, and K. Graetz, "Procrastination in online courses: Performance and attitudinal differences", Teaching of Psychology, vol. 30, no. 2, pp. 159-162, 2003.

[36] L. Rourke, T. Anderson, D.R. Garrison, and W. Archer, "Assessing social presence in asynchronous text-based computer conferencing”, The Journal of Distance Education, vol. 14, pp. 5071, 2007.

[37] K. Swan, "Relationships between interactions and learning in online environments", The Sloan Consortium, 2004.

[38] J. Koh, and Y.G. Kim, "Sense of virtual community: A conceptual framework and empirical validation", International Journal of Electronic Commerce, vol. 8, pp. 75-94. 2003

[39] M.H. Hsu, T.L. Ju, C.H. Yen, and C.M. Chang, "Knowledge sharing behavior in virtual communities: The relationship between trust, self-efficacy, and outcome expectations", International Journal of Human-Computer Studies, vol. 65, pp. 153-169, 2007.

[40] A. Kankanhalli, B.C.Y. Tan, and K.K. Wei, "Contributing knowledge to electronic knowledge repositories: An empirical investigation”, MIS Quarterly, vol. 29, pp. 113-143, 2005.

Received: June 10, 2015

Revised: July 29, 2015

Accepted: August 15, 2015

(C) Bo Shen; Licensee Bentham Open.

This is an open access article licensed under the terms of the (https://creativecommons.org/licenses/by/4.0/legalcode), which permits unrestricted, noncommercial use, distribution and reproduction in any medium, provided the work is properly cited. 